\title{
future internet
}

ISSN 1999-5903

www.mdpi.com/journal/futureinternet

Article

\section{The U-City Paradigm: Opportunities and Risks for E-Democracy in Collaborative Planning}

\section{Francesco Rotondo}

Department of Architecture and Town Planning, Bari Polytechnic, via Orabona 4, Bari 70126, Italy; E-Mail: f.rotondo@poliba.it; Tel.: +39-347-595-7508; Fax: +39-080-964-1317

Received: 25 January 2012; in revised form: 5 March 2012 / Accepted: 22 May 2012 /

Published: 5 June 2012

\begin{abstract}
Volunteered Geographic Information (VGI) tools appear to enhance the possibilities offered by a collaborative approach to planning. The present paper analyzes both the results of experiences of the author and of those available in the literature, highlighting possible advantages and disadvantages. After a brief introduction to the meaning of e-democracy, the second part focuses on the role of ICT in collaborative planning, proceeding in the third part to an illustration of an initial panorama of knowledge gathered using ICT in such processes, while discussing criticisms and opportunities. The fourth part discusses the U-city paradigm as a driver of change in urban planning participation processes. Research perspectives are then outlined in the final part.
\end{abstract}

Keywords: e-democracy; collaborative planning; participation in planning

\section{Introduction}

Democracy, as well as e-democracy, requires participation (e-democracy presupposes it in the form of e-participation).

Any analysis, therefore, on the issue of e-democracy must begin from a consideration of participation as a prerequisite for a clear understanding of both e-participation and e-democracy. Representative democracy requires participation in voting processes, while deliberative democracy requires more complex and interactive forms of participation [1].

Thus, any distinction between representative and deliberative democracy should necessarily lead to a similar distinction made between representative e-democracy and deliberative e-democracy. Nevertheless, e-democracy is often presented as a process producing deliberative forms of interaction and participation online. Indeed, e-democracy requires e-participation. 
Problems associated with participation (as well as e-participation) are frequently presented as issues of redistribution of power between rulers and the ruled, as demonstrated in the first ladder of participation, as proposed by Sherry Arnstein [2] which remains the best-known and most frequently cited of such models.

The highest degree of participation is particularly difficult to achieve as we, generally, live in representative democracies. While this may lead to greater information and consultation with citizens, their ability to effectively take decisions is minimal. Best practice in participation is limited to including processes such as shared visions or participative project actions.

Most of the time, citizens would simply appreciate some control of, as well as a better understanding of, policy implemented by their delegates.

One of the most significant limitations of e-democracy in Italy would appear to be the belief that participation is to be understood only in the terms presented by Arnstein: participation as the formalization of a decision. Citizens are, on the other hand, at times convinced that the problem is not a new decision but, rather, control of the manner in which it is applied [3]. For the political class, therefore, the perception of control by engaging citizenship remains that of Arnstein, while active citizenship is to be understood as a verification of the outcome of a resource (the concept of participation is thus considered as a process of control while active citizenship is interpreted as an audit).

\section{The Role of ICT in Collaborative Planning}

Collaborative practices in spatial planning may be understood on a range of levels. Frequently such practices can be limited to an institutional level or may be extended to stakeholders (entrepreneurs, union representatives, consultancy organizations etc.), engage residents or, in limited cases, may even be initiated by citizens themselves in order to promote new actions or modify institutional processes denied to them (self-empowerment processes [4]). In such cases ICT today plays a fundamental role in ensuring high-level relationships between participants (see, for instance, the experiences described in [5]).

Empowerment processes aspire to design plans, providing answers to the needs of citizens, with or without the involvement of institutions (in the experience of the author, as described in [5,6]).

A collaborative approach to planning requires large-scale consensus on choices to be implemented and highlights the role of negotiation as a method for resolving conflict that may arise among the different interested parties [7-9].

Following on from this basic principle, successful processes promoted by citizens would appear to be those able to integrate institutions as members of the "same team", respecting the rules of what Healey described as "an inclusive dialogue" ([10] p. 284).

The present work therefore considers Healey's institutional approach to be of central importance, inspiring some central reflections on collaborative planning.

Healey's approach sees collaboration as a form of distribution of power, achieved through communication and dialogue. According to Habermas [11] and Forester [1], planning conflicts are better faced using strategic weapons such as social learning that can lead to effective agreement on results, rather than the standard weapons of ideological battles.

Through this approach, pragmatic knowledge deriving from daily practice and local tradition has the same relevance of knowledge possessed by the experts in the various professional fields who 
generally work in a given territory. Following certain views as expressed by Shon [12], common and expert knowledge must be considered in their totality, avoiding distortions produced by different perspectives thanks to the correct use of communication, and thus in this sense adopting.

In a collaborative approach, the real social and political capital created is represented by a growing trust in the players involved in mutual learning processes and a better understanding of the relationships existing among the participants. Furthermore, such practices of consensus building may fundamentally alter ways of considering a territory, transforming the basis of underlying relationships by integrating, in an inclusive dialectic, the various modes of experiencing the territory and the myriad of players inhabiting it as the possessors of different cultures. In this way, such practices may become clear forms of social empowerment [4].

Such basic principles have served as the starting point for a series of reflections on the role of the planner, on planning arenas, on planning practices and styles and on methods for building and maintaining consensus ([10] p. 264, 265).

Planning thus requires, in this context, consideration of coordinated actions and a special attention towards communication within societies that must be satisfied in order to ensure the effective coordination of actions and that the needs of the different decisional agents are met [11]. ICT methods can provide fundamental support for communication needs in multi-agent decisional processes, increasing data access and levels of information, thereby enhancing knowledge levels of the specific issues and process dynamics [13].

This approach would appear to be more easily implemented by means of the developing possibilities of interaction proposed by ICT. This does not simply imply the facilitation of communication. Such instruments could, when integrated alongside other IT tools, help in building and spreading knowledge through a collaborative process drawing on the open use of alphanumerical and/or geographical databases. This would allow for interpretation as the cognitive base element on which design hypotheses of a plan could be established.

Planning contexts generally equate to public contexts, characterised by a high degree of inertia towards change, in which the use of ICT promises enormous potential yet, at the same time, undoubtedly poses significant risks and limitations. The latter serve as the focus for numerous research projects within the field of organization theory. Within the sphere of policy analysis and spatial planning, interaction between actors is, expected to reach agreement on decision-making by means of conflict management and resolution (as notably illustrated by Fischer and Forester, [14]).

\section{Lessons Learnt Using ICT in Collaborative Planning}

\subsection{Introduction}

A collaborative planning process must ensure the possibility for all involved to participate in each phase of the process, engaging them in the ongoing debate, providing the possibility to present opinions [15].

Such a process of mutual learning can produce a common knowledge base between all involved which may, indeed, serve as one of the most significant results achieved by the collaborative planning 
process, enhancing the social value of the chosen solution. One of the major challenges for planners may be, in collaborative environments, how best to collect, manage and summarize the knowledge of citizens.

Indeed, such knowledge is generally expressed in descriptive forms (stories, anecdotes, examples, memories and so on), which are difficult to "process" in a computer and utilize as operative indications for planning actions, which normally require prescriptive, regulating judgments (zoning, regulations, norms, etc.).

A further consideration, in addition to the management of the knowledge of citizens, is the generally highly time-consuming nature of collaborative processes and procedures, both for participants and facilitators. Indeed, frequently, after a first period of engagement, participants become tired of participating in what it appears to be an eternal process. This has led to certain such processes in the United Kingdom providing participants with some level of retribution. It would appear that both issues could be tackled through the use of information and communication technologies (ICT) in order to support the activities of working groups (such as district committees or, more generally, citizen groups meeting in order to promote a certain initiative or to oppose an institutional decision) and simplify interaction among the different decisional agents involved [9].

\subsection{Critical Features}

This paragraph examines various critical aspects observed during experiences over recent years $[5,6,16]$ in comparison to the literature on the same theme: building up shared knowledge through on-line brainstorming sessions. In these experiences, the difficulties encountered by participants in expressing their ideas through computer-based technologies are often related to an overall difficulty in using ICT, a well-documented problem, commonly referred to in literature as the "digital divide".

It has been demonstrated that, in addition to this established barrier, the computer-mediated environment is, for participants, undoubtedly colder and less stimulating than a traditional face-to-face meeting. The use of a chat function appears to alleviate the monotony of a computer-mediated session, yet IT brainstorming generally fails to feature the informal, enjoyable interface that develops in traditional meetings $[6,17,18]$.

It has been noted that, particularly in "same time, different place" on-line sessions, the lower level of interaction occurring amongst participants is often intensified by the lack of feedback among participants, which was only provided at the end of the round of answers, as demonstrated in [19,20].

Such negative features are, however, offset by a series of positive ones, illustrated in the following paragraphs, whose significance calls for further testing of IT tools in such contexts.

\subsection{Positive Features}

The Internet and IT tools present significant opportunities in terms of their exploitation in the collaborative planning arena. Such opportunities are of equivalent significance to the use of the Web in any operative context, but their value becomes particularly evident in the context of e-government policy. Others are specific in terms of the use of IT tools and the Web in establishing participatory methodologies in the collaborative planning field.

The Internet can mitigate, or even eliminate, geographical distance. It can therefore also increase participation among the disabled or those with reduced mobility, favouring equal access to the 
participation process. Further positive aspects of employing ICT in collaborative planning include the accomplishment speeds of different on-line activities [20] and the transparency and traceability of the actions and opinions of different contributors. Pathways explored during the collaborative process can be illustrated through documents, photos, audio and video protocols of meetings, allowing for the knowledge acquired to be stored and kept for posterity as a "collective memory".

This is a significant aspect of collaborative planning processes, as the large number of people involved and the non-linear evolution of the process (which commonly start out enthusiastically, are slowed down at the first delay only to start up again under the stimulus of new agents) may produce a particularly long-term process. Collaborative planning processes are thus at serious risk of overlooking the series of events that have structured the process itself as well as the potentially considerable benefit offered by ICT in reviewing the range of positions expressed in earlier meetings and debates.

A well-constructed, continually updated, web site with rich content in terms of news and documents, thus permits those absent at the beginning of the process to become involved at a later stage, more easily rebuilding (compared to the pre-IT age) the crucial stages of the path followed by initial participants [18]. Brainstorming, focus groups, and enacting scenarios developed with ICT tools with reference to case studies as already described by the authors [5,6], could have further, highly significant, advantages.

Firstly, the method in which the knowledge of citizens is stored is highly appropriate to a computer and readily manageable (as in the case of Public Participation Geographical Information Systems; PPGIS), as such data has been recorded on the computer from the beginning. Indeed, having searched for prospective geographical relations present in the audio and video protocols of meetings, links may be made between opinions, memories and desires and places, aiming to construct a "geography" of participants' knowledge. Following on from this phase, such information can be represented in spatial cognitive maps suitable in supporting more informed decisions. It is well known, in fact, that a cognitive map may be defined as "an overall mental image or representation of the space and layout of a setting" [21]. Furthermore, on-line participation methods (brainstorming, focus groups, and so on) evidently provide faster responses and a far more manageable collection of thoughts and suggestions than traditional methods.

Moreover, the possibility to immediately assess the results of a session, in the form of graphs or text reports, allows for an almost immediate assessment of a meeting, not only by the organizers of the session but also by participants themselves. This significantly decreases timescales in re-arranging structured meetings during a collaborative process, which would otherwise be a highly time consuming procedure when carried out using traditional methods [22].

It should be noted that, in the opinion of the author, the use of IT tools and the Web in supporting collaborative planning does not remove the need for face-to-face meetings. It does, however, lead to such meetings being located in a more conscious environmental context, as underlined by Beamish [19] in the field of Community Networks, offering participants the possibility to better organize meetings and to analyse all relevant documentation as and when needed. 


\section{The U-City Paradigm Drives Change in Urban Planning Participation}

\subsection{Introduction}

A ubiquitous city or U-city is a city with an Ubiquitous Computing Environment [23]. All information systems are linked, and virtually everything is linked to an information system through technologies such as wireless networking. It is in Korea that this new concept of Ubiquitous-City (U-City) has attracted attention in the last ten years [24]. The aim is to fuse a high-tech infrastructure and an ubiquitous information service into the urban area. It is also thought to bring innovations to urban functions.

This concept was born in early 1990s when Mark Weiser [25] proposed an Ubiquitous Computing project at the Xerox Palo Alto Research Centre in the US. He provided a vision of a built up environment whose digital networks link individual residents, not only to other people but also to goods and services, whenever and wherever they are needed. Since then the Republic of Korea, on considering the results of that project, has been continuously developing national strategies for knowledge based urban development through the agenda of many e-development programs such as Cyber Korea, E-Korea and U-Korea.

In the contemporary society, wiki-based collaboration technologies, Web mapping, cellular telephones and Global Positioning Systems (GPS) have gone well beyond the traditional spatial data infrastructure architectures already widespread around the world [26,27], expanding upon the possibilities created by other ICT tools for collaborative planning such as those considered in the previous paragraph.

Web Collaborative-mapping functions similarly to Open Street Map (see Figure 1) or Google Map Maker, provide both experts and novices alike with the possibility of producing and sharing oriented geospatial information.

Figure 1. An example of an Open Street Map created by the author for the University Campus in the city of Bari (Italy), highlighting shops and services present in the area and the new building of the Faculty of Architecture.

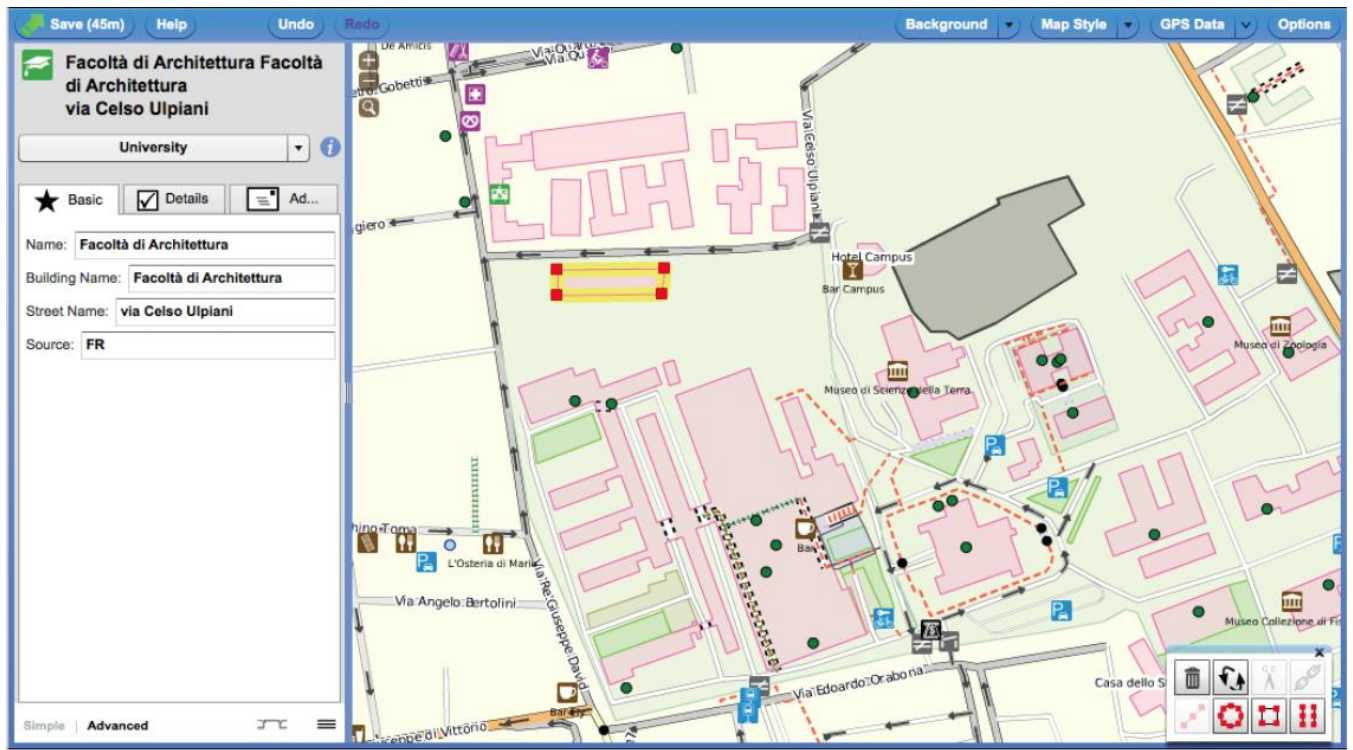


The concept of "user-generated content" is already highly familiar in planning participation knowledge.

There are numerous examples of PPGIS in which participants have proposed input and feedback to professionals and communities of interest in both roundtable and Web-based settings [28,29].

The difference between such practices and the role assumed by the community in the Web 2.0 approach is fundamental. This role, and the conditions in which it may be executed is, in essence, explained by Bruns [30] when describing four fundamental features of informational "produsage" as distinct from informational "production":

(1) Community based: collaborative engagement of large communities of participants in a shared project, exploiting the 'Power of Eyeballs' and the 'Long Tail' of diverse knowledge, abilities and interests outside a narrow elite of knowledge workers;

(2) Fluid roles: the necessity to allow for a fluid movement of individual "produsers" between different roles within the community;

(3) Unfinished artefacts: the "palimpsestic" nature of volunteered or "prodused" content-resembling the repeatedly overwritten pages of ancient texts that hold the latest version and the history of examination, discussion and alteration of the artefact;

(4) Common property-individual merit: members of the produsage community adopting more permissive approaches to legal and moral rights in intellectual property than those found in traditional content production.

At the same time, Turner [31] created the term "neo-geography" described as "geographical techniques and tools used for personal activities or for utilization by a non-expert group of users; not formal or analytical".

Simultaneously, Goodchild [32] coined the term "Volunteered Geographic Information" (or VGI) outlined as the harnessing of tools to create, assemble, and disseminate geographic data provided voluntarily by individuals, who create their own content by marking locations where various events may occur or certain features exist.

These terms as described are frequently used to refer to individuals creating their own maps, geo-tagging pictures, movies, websites, etc. Such user behaviour has been defined as a bottom-up approach to geography [33].

Considering the potential of these new tools, it can be argued that as technologies (e.g., GPS, remote sensing, etc.) may be helpful in producing new spatial data, voluntary activities may be a suitable and "low-cost" method of bringing such data up-to-date while describing it in an informal, more accessible manner to citizens. It would appear obvious that numerous public and private mapping institutions should be interested in maintaining their data up-to-date, yet it is not necessarily clear how an organization evaluates the trustworthiness of a new creator and the degree of confidence it may have in their inputs.

The level of trust in such information is, in the opinion of the author, a fundamental issue to be addressed in developing such tools in institutional activities and processes.

Nevertheless, our major interest as urban planners is not attempting to respond to the previous question but, rather, understanding how a Web 2.0 approach may encourage participation in urban planning processes, reinforcing the role of ICT in collaborative practice, simplifying, or not, the planning process in terms of its effectiveness in communication. 
The following paragraphs will, therefore, attempt to explain what specific opportunities and operational risks such technologies may pose to sustaining participation in urban planning during this very early phase of application.

\subsection{Opportunities}

Employing ICT in support of a collaborative planning process could expand possibilities in terms of producing both knowledge and geographical information.

Indeed, younger generations in particular could take advantage of these new tools in order to illustrate their views of a place, revealing a geography of community, of great significance to a planner in supporting deliberation within spatial decision-making.

This represents an almost autonomous method for an individual to shape his or her own image of the city, just as Lynch [34] has exemplified in fundamental work focusing on the city of Boston.

Indeed, Lynch's work revealed the results of a five-year study on how users perceive and classify spatial information as they navigate through cities. Testing the method in three different cities (Boston, Jersey City, and Los Angeles, USA), Lynch demonstrated that users "read" their urban environments in regular and predictable ways, building upon five elements which, following on from the study, became known as mental maps or cognitive maps:

- Paths: the streets, sidewalks, trails, and other routes along which people travel;

- Edges: perceived boundaries such as walls, buildings, and shorelines;

- Districts: relatively large sections of the city distinguished by some specific identity or character;

- Nodes: focal points, intersections or loci;

- Landmarks: readily identifiable objects which serve as external reference points.

A central notion of the work is that of legibility (also referred to as imageability and visibility). Legibility refers to the extent to which the cityscape may be read. People who navigate through the city engage in way-finding: "In the process of way-finding, the strategic link is the environmental image, the generalized mental picture of the exterior physical world that is held by an individual. This image is the product both of immediate sensation and of the memory of past experience, and it is used to interpret information and to guide action".

On analysis, it is noted that Volunteered Geographical Maps are frequently characterised by the same five elements described by Lynch.

Considering that such tools are not simply associated to one planning process but are, rather, created through continuous and free activity, uniquely plotted by each participant, it is evident that after a certain period of development, the "open street map" becomes a rich and intriguing "geographical diary" of the community involved.

Consulting an up-to-date "geographical diary", planners could represent the social patrimony of the city through structuring a plan, combining it with natural patrimony, shaping sites.

This represents, therefore, one of the principal potential relations between the concept of wiki mapping and the necessity of up-to-date, participative planning information.

Planners generally try to obtain such social representation of territories through a swift and well-organised participation process (this could include, for example, traditional methods of 
brainstorming, focus groups and outreach strategies generally employed in participation processes), usually managed on a PPGIS. This represents a more "process oriented" method than "free" maps, but the latter boasts the latent benefit of being always available and, at least potentially, up-to-date; at the same time they may also prove to be a highly valuable starting point for more advanced studies carried out expressly for a planning process. Evidently, the use of Volunteered Geographical Maps does not exclude the possibility of carrying out the swift and well-organised participation processes as described above, expressly performed for a particular plan. Finally, if we accept the view of Patsy Healey [35] that "the idea of planning carries with it an orientation to the future, an emphasis on liveability and sustainability, an emphasis on interdependences and connectivities, a grounding in knowledge about the interactions between people and place, and a commitment to transparency in policy making". Subsequently Volunteered Geographical Maps could assist in representing such interactions between people and place, in an independent and continuous manner.

\subsection{Risks for Urban Planning Participation Processes}

Despite potential positive aspects, the effective employment of Web 2.0 tools in collaborative planning remains limited. Despite the significant number of existing "Volunteered Geographical Maps" and the numerous articles in research literature on these new tools, it would appear that such tools are not yet effectively integrated in the participative planning process and are even less frequently employed in the deliberative decision making process.

Web 2.0 approaches offer the possibility for users to become "produsers" of geographic information [36], a new perspective on the role of individuals in the planning process, yet also raising the possibility of impeding planning actions and debate with what may be referred to as "geo-information overload".

Indeed, as with YouTube, or in the realm of public chat or blogs, users are free to publish images and comments; geo-tagging presents the same possibility with geographical objects. Given that urban planning is universally recognized as a fragile process in which the opinions of communities and stakeholders are easily changeable over time, the possibility of having numerous different tags for the same spatial object could generate possible confusion in the same individuals and stakeholders.

Furthermore, the ability to publish news in real time and at almost no cost, allows anyone to offer an opinion on facts, places and people without any means of verification, making the web the ideal space for defamation, more similar in nature to community gossip than real news.

One of the major risks of a "geo-information overload" could be what the psychologist James Reason [37] has referred to as "confirmation bias", explained as the tendency to confirm an idea or to authorize what we have "learnt", despite evidence demonstrating the contrary.

This natural human tendency is confirmed by a range of features characterizing contemporary society such as the lack of time available for reviewing our own position or the great quantity of information we must manage, particularly on the Web.

From the point of view of geographical discipline, it should be noted that the opportunity to comment on geo-referenced geographical objects does not necessarily, therefore, render user comments as geo-referenced themselves. 
For instance, summaries of posted information are frequently difficult to generate despite the fact that geographic references and spatial relations could be used to integrate and condense geo-tagged media.

Furthermore, it could be very useful for spatial planning to comprehend the interest in certain places as highlighted by communities, as would analysing the frequency of inputs provided by volunteers on a specific map, with geo-tagging frequencies serving as an indicator for levels of interest in a specific location.

\section{Research Perspectives}

The development of ICT and Web 2.0 tools with VGI can provide new tools for dealing with old problems through a contemporary approach, conceivably more compatible to the complexities of multi-player and multi-agent decisional environments.

The present work has, of course, developed only a few preliminary thoughts on both positive and negative aspects of using VGI in urban planning participation processes, yet the subject remains so fertile and potentially rich that time must allow for a full and in-depth analysis of both practice and results.

Nevertheless, urban planning participation via Web 2.0 tools goes forward, aiming to define problems, guaranteeing the same possibilities for communication for each of the different players involved and assessing contingent or long term interests (e.g., environmental issues).

In contemporary society in which processes are complex and fuzzy, we can attempt to use PPGIS and VGI in order to draw cognitive spaces, the space of natural discourse built by individuals through collaborative planning. We can attempt to collect and translate "mental maps" of boundaries, locations and zones into geo-referenced mappable outputs.

The need to listen to several "voices" and rely on multiple knowledge sources in contemporary planning requires the use of technologies and tools that can manage multiple data in the most efficient time and effective way. This is the purpose of the hunt for the search for on-line informatics tools to support collaborative planning.

\section{References}

1. Forester, J. The Deliberative Practitioner, Encouraging Participatory Planning Processes; MIT Press: Cambridge, MA, USA, 1999.

2. Arnstein, S.R. A ladder of citizen participation. J. Am. Inst. Plan. 1969, 35, 216-224.

3. Gangemi, G. L'e-democracy Come Risvolto Tecnologico Della Partecipazione. In L'evoluzione dei Modelli e Delle Tecnologie per la Partecipazione dei Cittadini: L'esperienza del Consiglio Regionale del Veneto; de Pietro, L., Ed.; Marsilio Editori: Padova, Italy, 2010.

4. Friedmann, J. Planning in the Public Domain: From Knowledge to Action; Princeton University Press: New York, NY, USA, 1987.

5. Rotondo, F. Utility of Web and Electronic Meeting Systems Supporting Collaborative Planning. In The Electronic City; Bucher, U., Finka, M., Eds.; Berliner Wissenschafts-Verlag BWV: Berlin, Germany, 2008. 
6. Rotondo, F.; Selicato, F.; Torre, C. A collaborative approach to an environmental planning process: The "Lama Belvedere" urban park in Monopoli. Available online: http://www.planum.net/ community-planning/a-collaborative-approach-to-an-environmental-planning-process-the-lamabelvedere-urban-park-in-monopoli (accessed on 20 May 2012).

7. Barbanente, A.; Borri, D. Reviewing self-sustainability. Plurimondi 2000, II, 5-19.

8. European Commission (EC). Report on Community Policies and Spatial Planning; Working Document of the Commission Services for the Elaboration of the ESDP: Brussels, Belgium, 1998.

9. Laurini, R. Information Systems for Urban Planning; Taylor and Francis: London, UK, 2001.

10. Healey, P. Collaborative Planning: Shaping Places in Fragmented Societies; Macmillan Press: London, UK, 1997.

11. Habermas, J. Theorie des Kommunikativen Handelns; Suhrkamp: Berlin, Germany, 1981.

12. Shon, A.D. The Reflective Practitioner: How Professionals Think in Practice; Basic Books: New York, NY, USA, 1983.

13. Shiffer, M.J. Towards a collaborative planning system. Environ. Plan. B Plan. Des. 1992, 19, 709-722.

14. Fischer, R.; Forester, J. The Argumentative Turn in Policy Analysis and Planning; Duke University Press: Durham, London, UK, 1993.

15. Innes, J. Consensus building: Clarifications for the critics. Plan. Theory 2004, 3, 5-20.

16. Rotondo, F.; Selicato, F. E-democracy in collaborative planning: A critical review. Lect. Notes Comput. Sci. 2011, 6783/2011, 199-209.

17. Sillince, J.A.A.; Saeedi, M.H. Computer-mediated communication: Problems and potentials of argumentation structures. Decis. Support Syst. 1999, 26, 287-306.

18. Ishida, T.; Nakanishi, H.; Isbister, K.; Okamoto, M. Supporting cross-cultural communication with a large-screen system. New Gener. Comput. 2002, 20, 165-185.

19. Beamish, A. Communities On-Line: Community-Based Computer Networks. M.S. Thesis, Massachusetts Institute of Technology, 1995. Available online: http://sap.mit.edu/anneb/cn-thesis/ (accessed on 9 November 2002).

20. Mitchell, W.J. Equitable Access to the Online World. In High Technology and Low-Income Communities: Prospects for the Positive Use of Advanced Information Technology; Schon, D.A., Sanyal, B., Mitchell, W.J., Eds.; MIT Press: Boston, MA, USA, 1998.

21. Arthur, P.; Passini, R. Wayfinding: People, Signs, and Architecture; McGraw-Hill: Toronto, Canada, 1992.

22. Nunamaker, J.F.; Briggs, R.O.; Mittleman, D.D. Electronic Meeting Systems: Ten Years of Lessons Learned. In Groupware: Technology and Applications; Coleman, D., Khanna, R., Eds.; Prentice Hall: Upper Saddle River, NY, USA, 1995.

23. Jang, M.; Suh, S. U-City: New Trends of Urban Planning in Korea Based on Pervasive and Ubiquitous Geotechnology and Geoinformation. In Computational Science and Its Applications-ICCSA 2010; Taniar, D., Gervasi, O., Murgante, B., Pardede, E., Apduhan, B., Eds.; Springer: Heidelberg, Germany, 2010; pp. 262-270. 
24. Lee, S.H.; Han, J.H.; Leem, Y.T.; Yigitcanlar, T. Towards Ubiquitous City: Concept, Planning, and Experiences in the Republic of Korea. In Knowledge-Based Urban Development: Planning and Applications in the Information Era; Yigitcanlar, T., Velibeyoglu, K., Baum, S., Eds.; IGI Global: Hershey, PA, USA, 2008; pp. 148-169.

25. Weiser, M. Hot topics: Ubiquitous computing. IEEE Comput. 1993, 26, 71-72.

26. Goodchild, M.F. NeoGeography and the nature of geographic expertise. J. Locat. Based Serv. 2009, 3, 82-96.

27. Craglia, M.; Goodchild, M.; Annoni, A.; Camara, G.; Gould, M.; Kuhn, W.; Mark, D.; Masser, I.; Maguire, D.; Liang, S.; et al. Next-generation digital earth: A position paper from the vespucci initiative for the advancement of geographic information science. Int. J. Spat. Data Infrastruct. Res. 2008, 3, 146-167.

28. Al-Kodmany, K. Visualization tools and methods in community planning: From freehand sketches to virtual reality. J. Plan. Lit. 2002, 17, 189-211.

29. Craig, W.J.; Harris, T.M.; Weiner, D. In Community Participation and Geographic Information Systems; Taylor \& Francis: London, UK, 2002.

30. Bruns, A. Towards Produsage: Futures for User-Led Content Production. In Proceedings of Cultural Attitudes towards Communication and Technology; Sudweeks, F., Hrachovec, H., Ess, C., Eds.; Murdoch University: Perth, Australia, 2006; pp. 275-284.

31. Turner, A. Introduction to Neogeography; O’Reilly Media: Oxford, UK, 2006.

32. Goodchild, M.F. Citizens as voluntary sensors: Spatial data infrastructure in the world of Web 2.0. Int. J. Spat. Data Infrastruct. Res. 2007, 2, 24-32.

33. Coleman, D.J.; Sabone, B.; Nkhwanana, N. Volunteering geographic information to authoritative databases: Linking contributor motivations to program effectiveness. Geomatica 2010, 64, 383-396.

34. Lynch, K. The Image of the City; MIT Press: Cambridge, MA, USA, 1960.

35. Healey, P. Making Better Places; Macmillan Press: London, UK, 2010.

36. Rinner, C.; Kessler, C.; Andrulis, S. The use of Web 2.0 concepts to support deliberation in spatial decision-making. Comput. Environ. Urban Syst. 2008, 32, 386-395.

37. Reason, J. Human Error; Cambridge University Press: New York, NY, USA, 1990.

(C) 2012 by the authors; licensee MDPI, Basel, Switzerland. This article is an open access article distributed under the terms and conditions of the Creative Commons Attribution license (http://creativecommons.org/licenses/by/3.0/). 